\title{
Entrevistas preliminares: o caso da "jovem homossexual” de Sigmund Freud ${ }^{\star}$
}

\author{
Anamaria Batista Nogueira (iD $\star \star$ \\ Universidade Federal de Minas Gerais, Belo Horizonte, MG, Brasil
}

\begin{abstract}
Resumo
Ao pesquisarmos sobre o tema das entrevistas preliminares, somos automaticamente levados a pensar na posição do analista e no seu manejo clínico. Alguns pacientes demandam o próprio tratamento, outros nos procuram pelo intermédio de terceiros. É preciso pensar na posição do analista diante da demanda daquele que o procura, ou mesmo se é possivel ao analista fazer surgir a demanda em um paciente que foi induzido a seu encontro. A esse respeito, Freud nos apresenta um trabalho clínico publicado sob o título "A psicogênese de um caso de homossexualismo numa mulher". A psicanálise freudiana se apresenta muito à frente de seu tempo ao romper com um discurso heteronormativo diante da temática sobre a escolha por um objeto amoroso, o que nem sempre é benquisto, inclusive nos tempos atuais. O autor foi de extrema generosidade ao expor um caso clínico em que a sua posição, como analista, pode ser contestável.
\end{abstract}

Palavras-chave: entrevistas preliminares; demanda; transferência; vergonha.

\section{Preliminary interviews: the case of a "young homossexual woman" of Sigmund Freud}

\begin{abstract}
Research on the subject of preliminary interviews often lead us to think of the analyst's role and the clinical management in receiving and interacting with a patient. Some patients seek treatment on their own whereas some patients seek therapy recommended by others. It is important to understand the analyst's role for those who seek treatment and also the possibility for the therapist to create a demand for those patients who were lead to him. In regards to that matter, Freud (1920-1922/1996) published a clinical work entitled The Psychogenesis of a Case of Homosexuality in a Woman. Freudian psychoanalysis is very much ahead of its time by breaking with a heteronormative discourse facing the theme about the choice for a loving object, which is not always well-liked, even in the present times. The author generously discusses a clinical case in which his role as an analyst could be questionable.

Keywords: preliminary interviews; demand; transference; shame.
\end{abstract}

\section{As entrevistas preliminares: um convite ao analista}

Freud recebeu em seu consultório os pais de uma jovem, que o procuraram a fim de que ele, posteriormente, conduzisse o tratamento da filha. Tratava-se de uma jovem de 18 anos e de sua adoração e perseguição a uma mulher 10 anos mais velha que ela, uma "dama da sociedade". Conforme o relato desses pais, esta dama vivia e tinha relações íntimas com uma mulher, e também se relacionava sexualmente com alguns homens (FREUD, 1920-1922/1996, p. 159).

Ao que tudo indica, a dama rejeitava os investimentos de sua jovem admiradora, mas a tratava de forma amistosa, depois que ela tentou suicídio. Com a recuperação da jovem, seis meses após o ocorrido, seus pais a conduziram ao tratamento psicanalítico no intuito de confiar a Freud a tarefa de reconduzi-la a um "estado normal de espírito" (FREUD, 1920-1922/1996, p. 160).

A condução da jovem a Freud só foi possível porque os pais da moça se deram conta da impotência de suas "fortes medidas disciplinares" em relação ao "distúrbio" da própria filha (FREUD, 1920-1922/1996, p. 160). Nenhuma medida tomada pelos pais em relação às

\footnotetext{
^Agradeço à Capes, ao setor de pós-graduação da UFMG e à Universidade Newton Paiva pelo apoio no desenvolvimento deste trabalho.

$\star \star$ Endereço para correspondência: Av. Prudente de Morais 287, sala 910. Santo Antônio - Belo Horizionte, MG - Brasil. CEP: 30350-093. E-mail: ananogueirapsi@gmail.com

Os dados completos da autora encontram-se ao final do artigo.
}

parcerias amorosas da filha era suficientemente forte para contê-la. O tratamento psicanalítico, desde já, é colocado nesse lugar, de fazer valer certa posição do par parental em relação às escolhas amorosas da filha. Caso a psicanálise "falhasse", o pai tinha em mente outro plano, "[...] ele ainda tinha de reserva sua mais forte medida defensiva: um casamento rápido deveria despertar os instintos naturais da moça e abafar suas tendências inaturais" (FREUD, 1920-1922/1996, p. 160).

Esse caso nos apresenta uma demanda de tratamento clara e direta feita ao analista. Os pais, em especial o pai, demandam a cura da jovem em relação à homossexualidade. Nesse sentido, caberia ao analista a "tarefa" de remover a "inversão genital", ou seja, de reverter a homossexualidade da paciente. Porém, “[...] o homossexual não é capaz de abandonar o objeto que o abastece de prazer e não se pode convencê-lo de que, se fizesse a mudança, descobriria em outro objeto o prazer a que renunciou" (FREUD, 1920-1922/1996, p. 162).

Houve uma demanda muito específica e delicada dos pais da jovem à Freud, que reflete uma posição social central da época, segunda metade do século XX, tempos em que se esperava mais rigorosamente que o objeto amoroso fosse anatomicamente de sexo oposto ao próprio sexo, como uma espécie de coalizão. No entanto, não podemos deixar de levantar um ponto de extrema relevância: a posição ética de Freud em relação à homos- 
sexualidade. Sobre esse tema, a sua clínica não sucumbiu às exigências sociais de sua época, já que Freud se negou a associar como uma das possíveis funções do psicanalista a "cura gay". Podemos perceber essa posição clínica de Freud tanto no caso da "jovem homossexual" como em outros momentos de sua trajetória como psicanalista.

Em 19 de abril de 1935, Freud (1935/1967, p. 43), por meio de uma carta, responde à mãe de um jovem homossexual, a qual lhe pede ajuda em relação a seu filho; com isso, o psicanalista deixa clara sua posição:

A homossexualidade não é evidentemente uma vantagem, mas não há nada do que sentir vergonha. Ela não é nem um vício, nem uma desonra e não poderíamos qualificá-la de doença. [...] Muitos indivíduos altamente respeitáveis, nos tempos antigos e modernos, foram homossexuais (Platão, Michelângelo, Leonardo da Vinci, etc). É uma grande injustiça perseguir a homossexualidade como crime e também uma crueldade. [...] Ao me perguntar se eu posso lhe oferecer a minha ajuda, imagino que isso seja uma tentativa de indagar acerca da minha posição em relação à abolição da homossexualidade, visando substituí-la por uma heterossexualidade normal. A minha resposta é que, em termos gerais, nada parecido podemos prometer.

Freud desmistifica o entendimento sobre a homossexualidade em sua época ao afastá-la do caráter patológico, motivo que o impedia de prometer um tratamento no intuito de revertê-la.

Há, nessa mesma carta, outro posicionamento ético de Freud. Enquanto psicanalista, ele trabalha a demanda da mãe do jovem homossexual, ao deixar aberto o seu consultório a fim de tratar o jovem, desde que fosse por outros motivos que não a sua homossexualidade, como o "descontentamento por causa de milhares de conflitos e inibição em relação à sua vida social" (FREUD, 1935/1967, p. 43). Há tanto um acolhimento por parte de Freud a essa mãe como um manejo clínico à sua demanda.

Nos Três ensaios sobre sexualidade e outros trabalhos, Freud (1901-1905/1996) também nos leva a questionar sobre a articulação entre a escolha objetal e a fisiologia humana. Sobre um possível "interesse sexual exclusivo do homem pela mulher", não se trata simplesmente de "uma evidência indiscutível que se possa atribuir a uma atração de base química" (FREUD, 1901$1905 / 1996$, p. 138). Nesse sentido, a escolha de investimento em um objeto de desejo se distancia de uma causalidade biológica, tanto na homossexualidade quanto na heterossexualidade, conforme a teoria freudiana.

De volta ao caso da "jovem homossexual", outro impasse se interpõe entre a jovem e a sua possível análise. Segundo Freud (1920-1922/1996, p. 161), a jovem não apresenta um conflito interno, motivo que, em geral, levaria alguém a buscar o auxílio de um profissional diante da incapacidade de resolver o próprio problema, o que é comprometedor para a condição transferencial. Essa situação, por si só, já se apresenta completamente desfavorável ao processo analítico, como nos indica o autor.
Tendo em vista esses obstáculos ao tratamento psicanalítico, qual foi o posicionamento de Freud e o que ele nos ensinou sobre o posicionamento do analista tanto diante de uma demanda extraviada de tratamento vinda de terceiros quanto diante da falta de demanda da candidata a análise?

Mesmo com todos esses impasses, Freud (19201922/1996, p. 163) aceita o desafio de receber a jovem em seu consultório, e se abstém de oferecer aos pais dela alguma "perspectiva de realização de seu desejo", mas os acolhe! O psicanalista os diz que "[...] estava preparado para estudar cuidadosamente a moça durante algumas semanas ou meses, para então julgar em que medida uma continuação da análise teria probabilidade de influenciá-la" (FREUD, 1920-1922/1996, p. 163). Freud não promete cumprir o que lhe designa os pais da jovem, mas também não o nega. Desta forma, ele dá a chance de estabelecer uma relação transferencial com a jovem, e, com isso, abre margens à possibilidade de fazer surgir algum tipo de demanda de tratamento pela própria paciente.

Em relação ao processo analítico, Freud (19201922/1996, p. 163) o divide em dois momentos, que, por vezes, podem não estar tão nitidamente separados. No primeiro deles, o profissional se informa sobre o paciente, o familiariza com "as premissas e os postulados da psicanálise", e, a partir da dedução do "material trazido" pelo próprio paciente, o revela sobre "a reconstrução da gênese de seu distúrbio". Compreendemos essas primeiras sessões por entrevistas preliminares.

As primeiras sessões de um processo psicanalítico foram atribuídas de algumas maneiras por Freud (19111913/1996, p. 139) em seu artigo "Sobre o início do tratamento", como "tratamento de ensaio", "exame preliminar", "experimento preliminar", "entrevistas". Segundo Freud, essas entrevistas devem funcionar conforme as "regras da psicanálise", como, por exemplo, a associação livre, "[...] fazê-lo prosseguir no que está dizendo" (Freud, 1911-1913/1996, p. 140). Desta forma, possibilita-se um espaço para que se estabeleça a condição transferencial entre o paciente e o psicanalista, porém não visa à "cura".

Esse momento inicial do processo analítico, ainda segundo Freud (1911-1913/1996, p. 139), trata-se de uma espécie de "sondagem" para que o psicanalista possa "conhecer o caso e decidir se ele é apropriado para a psicanálise" e, em uma ou duas semanas, decidir-se a dar ou não continuidade ao tratamento, além de contribuir para o "diagnóstico diferencial". A esse respeito, de um lado situaria as neuroses, propensas ao processo analítico, e de outro a psicose, com a sua "fragilidade do ego", o que levava, nos tempos de Freud, a uma das "contra-indicações ao tratamento psicanalítico” (MILLER, 1999).

Uma outra função das "entrevistas preliminares", termo como se referia Lacan (1958/1998) nos Escritos aos primeiros momentos do processo psicanalítico, também coincide com a função do psicanalista. Diante de todo o processo de análise cabe ao psicanalista: "dirigir o tratamento" e não "dirigir o paciente" (LACAN, 1958/1998, p. 592). Aqui Lacan endossa o método da associação livre, o que é contrário a qualquer método sugestivo. 
O que nos desperta especial interesse na descrição de Freud sobre esse caso é a relação transferencial da jovem em relação a seu analista, mesmo que ela não apresentasse queixas e nem um conflito neurótico a ponto de advir alguma demanda de tratamento nas entrevistas preliminares. Segundo o autor, nesse primeiro momento a jovem não procura enganá-lo sobre a sua homossexualidade:

Ela não procurou enganar-me dizendo sentir alguma necessidade urgente de libertar-se de seu homossexualismo. Pelo contrário, disse ser incapaz de imaginar outra maneira de enamorar-se, mas acrescentou que, por amor aos pais, auxiliaria honestamente no esforço terapêutico, de vez que lhe doía muito ser-lhes a causa de tanto pesar (FREUD, 1969, p. 164).

Então, a jovem revela a Freud $(1969$, p. 176) alguns sonhos, que previam a sua "cura" por meio do tratamento, e que demonstravam a sua alegria e "anseio pelo amor de um homem e por filhos", o que, para o psicanalista, poderia ser considerado como "transferência positiva, como uma revivescência grandemente enfraquecida do original e apaixonado amor da jovem pelo pai”. Porém, o autor descreve sobre certa "contradição" entre esses sonhos e as "afirmativas da jovem na vida desperta", e conclui: "Os sonhos parcialmente expressavam o desejo de conquistar meu favor; eram também uma tentativa de ganhar meu interesse e minha boa opinião, talvez a fim de, posteriormente, desapontar-me mais completamente ainda" (FREUD, 1969, p. 176).

É nítido o avanço de Freud em relação ao processo analítico da jovem, por meio das entrevistas preliminares. Percebemos que a jovem, desde já, concebe certo lugar ao analista, ou pelo menos o convida a ocupar esse lugar. Um lugar que outrora fora exclusivamente, e de maneira mais intensa, ocupado pelo pai da moça. A transferência se interpõe entre Freud e a jovem, e o sonho a representa. Caberia ao analista, então, manejar esse lugar. A jovem, de alguma forma, foi fisgada pela presença do analista, já este passara de anfitrião a convidado - convidado a ocupar um lugar que lhe fora ofertado!

\section{$\mathbf{O}$ aceite}

Em "O primado do falo e a jovem homossexual", Lacan (1995, p. 103) recorre ao artigo de Freud (19201922/1996) "A psicogênese de um caso de homossexualismo numa mulher" e nos leva à compreensão, por meio da leitura de Freud, de que a vergonha se apresenta como uma concessão ao analista, o que se deve à situação transferencial. Para Lacan (1995, p. 107), a "jovem homossexual" assim se posicionava em relação a Freud: "tratava-se somente de mostrar a ele que ela o enganava". Mas como ela o demonstrou que o enganava?

Paralelamente às declarações não ambíguas que a paciente lhe faz de sua determinação de nada mudar em seu comportamento para com a dama, seus sonhos anunciam um surpreendente reflorescimento da orientação mais simpática, a espera da vinda de algum esposo belo e satisfatório, não menos que a da ocorrência de um objeto, fruto desse amor. Em suma, o caráter idílico, quase forçado, do esposo anunciado pelo sonho aparece tão em conformidade com os esforços empreendidos em co- mum que qualquer um que não fosse Freud tiraria dele as maiores esperanças (LACAN, 1995, p. 107).

Para Lacan (1995, p. 107), Freud percebe a situação transferencial de sua paciente, que se revela por intermédio do conteúdo de seus sonhos. A escolha homossexual, por meio da qual a libido da jovem destina-se a objetos do mesmo sexo, "[...] é uma resposta à decepção devida ao pai [...]", e o sonho revelado a Freud seria "[...] a duplicação dessa espécie de jogo de contralogro [...]" destinado também à figura do analista. Mesmo que, por meio do sonho, a jovem pareça enganar o seu analista, isso não quer dizer que a relação dela para com Freud seja representada por uma ausência da condição transferencial, e, sobre esse aspecto, "Freud não se engana" (LACAN, 1995, p. 107).

Quando Lacan se refere ao conteúdo desses tipos de sonhos como pertencente a um "jogo de contralogro", é porque esse conteúdo não era uma fraude, apesar de se tratar de uma mentira. $O$ conteúdo desses sonhos não era uma fraude em relação aos sentimentos da jovem referentes ao analista. Compreendemos que Lacan dá um destaque à revelação da jovem a Freud, por meio dos sonhos, que ela o enganava, o que se faz representar pela vergonha. A jovem não somente enganava o seu analista como o demonstrava. Não é em vão que, sobre o relato referente a esses sonhos, Freud o considerou como sendo a única expressão da jovem, no processo terapêutico, representante de uma "transferência positiva" em relação ao analista.

O conteúdo dos sonhos teria duas vertentes para Freud: se a jovem o enganava, era no sentido de que seu tratamento em relação à inversão de sua escolha objetal estaria sendo promissor, como queria os pais. Conquistá-lo, portanto, era uma vertente do sonho. Porém, Freud suspeita de que ela também queria desapontá-lo, assim como fazia com o pai.

Compreendemos que o conteúdo dos sonhos da "jovem homossexual" revela a Freud que sua paciente não estava disposta a colaborar com ele, em relação ao processo terapêutico, o que, para ela, concernia em abandonar sua escolha objetal. Nesse sentido, o sonho apresenta a resistência da jovem homossexual em relação ao processo analítico, mas, ao mesmo tempo, indica o estabelecimento da condição transferencial, o que, para Lacan, representa a condição de vergonha - ela demonstra ao analista que o engana.

Tendo em vista a interpretação de Lacan sobre o trabalho de Freud, no caso da jovem homossexual, conceder algo ao analista, que indica a situação transferencial, é um marco da condição de vergonha. Mas o que lhe é concedido?

Se a "jovem homossexual" propicia uma crise porque se frustra, como afere Lacan (1995, p. 110), deve-se à intervenção de um "objeto real", pois "uma criança é dada pelo pai, é verdade, mas justamente a outra pessoa, e a alguém que lhe é mais próximo".

Diante da frustração, como efeito, em questão de maior importância, destaca Lacan (1995, p. 110): “[...] o que é desejado está para além da mulher amada"; a relação da jovem com a dama não chegou às vias de fato, 
ou seja, tratava-se de um amor "cortês", “[...] que vive pura e simplesmente na ordem do devotamento". Esse amor foi uma saída encontrada pela jovem diante do desapontamento em relação ao pai. "No extremo do amor, no amor mais idealizado, o que é buscado na mulher é o que falta a ela. O que é buscado, para além dela, é o objeto central de toda a economia libidinal: o falo" (LACAN, 1995, p. 111). O amor em relação à dama é marcado pela falta, ou seja, “[...] é um amor que, em si, não apenas dispensa a satisfação, mas visa, muito precisamente, a não-satisfação" (LACAN, 1995, p. 109).

Lembramo-nos de uma passagem em que Freud (1969, p. 168) percebe um dos fundamentos que justificam a escolha da jovem pela dama: "A figura esbelta, a beleza severa e a postura ereta de sua dama lembravam-na seu irmão mais velho", irmão por meio do qual ela se deparara com o efeito de sua percepção sobre a diferença anatômica entre os sexos.

A análise demonstrou [...] que a jovem trouxera consigo, desde a infância, um 'complexo de masculinidade' fortemente acentuado. Jovem fogosa, sempre pronta a traquinagens e lutas, não se achava de modo algum preparada para ser a segunda diante do irmão ligeiramente mais velho; após inspecionar seus órgãos genitais [...] desenvolvera uma acentuada inveja do pênis e as reflexões derivadas dessa inveja ainda continuavam a povoar-lhe o espírito (FREUD, 1969, p. 180).

Compreendemos que a jovem concede uma pista a Freud sobre a sua forma de lidar com o Outro, o que, para Lacan, implica a condição da vergonha. Essa forma trata-se de uma relação fálica, faltosa. A jovem concede algo a Freud, ela possibilita ao analista interpretar o seu desejo de enganá-lo. Agradá-lo não é possível sem que haja um conflito, já que "o que se quer" não é passível de solução. Assim também podemos perceber por meio da forma como a jovem lida com o pai e com a dama, ou seja, seria da ordem de certa impossibilidade ter um filho do pai, e também chegar às vias de fato, por meio uma relação sexual, com a dama. A jovem se vê diante de um impasse em relação ao desejo e concede isso ao analista.

Pensamos, então, que, ao revelar ao analista que o engana por meio dos sonhos, ela lhe estaria propondo um "convite" a repetir a experiência da impossibilidade no campo do amor, tal como acontecera com o pai. Nesse sentido, ao que tudo indica, Freud acata esse convite, motivo pelo qual ele encerra o tratamento. Ele se sentira, de fato, enganado por ela, tal como ela fizera com o pai, e registrou esses sentimentos.

[...] ela me transferira o abrangente repúdio dos homens que a dominara desde o desapontamento sofrido com o pai. O azedume contra os homens, via de regra, é fácil de ser gratificado com o médico; não precisa evocar quaisquer manifestações emocionais violentas, simplesmente expressa-se pelo tornar fúteis todos os esforços dele e pelo aferrar-se à doença. Sei por experiência quão difícil é fazer um paciente entender precisamente esse tipo silencioso de comportamento sintomático e torná-lo ciente dessa hostilidade latente e excessivamente forte, amiúde, sem pôr em perigo o tratamento. Assim, logo que identifiquei a atitude da jovem para com o pai, interrompi o tratamento e aconselhei aos genitores que, se davam valor ao procedimento terapêutico, este deveria ser continuado por uma médica (FREUD, 1969, p. 175).

Mesmo que a vergonha seja colocada de modo en passant por Lacan no caso da "jovem homossexual", compreendemos que, nesse caso, a situação transferencial seria um indício da incidência da vergonha em relação ao analista. A vergonha representaria o lugar que a jovem estabelece para Freud, como analista, ou seja, o lugar que o sujeito concede ao Outro, e, por esse motivo, esse lugar não se trata de algo tão pessoal.

Para Freud (1969, p. 176), a jovem tentava conquistá-lo, para depois desapontá-lo “[...] mais completamente ainda”. Já para Lacan (1995, p. 108) o que a jovem concede a seu analista, e que demonstra ser uma relação marcada pela condição da vergonha, é o "desejo de enganar". Conforme Lacan (1995, p. 109), “[...] era simplesmente um desejo, e não uma intenção, de enganá-lo", porém, sobre Freud, "ele dá corpo a esse desejo". Para Lacan (1995, p. 108), Freud "[...] toma a coisa como dirigida contra ele", o que inviabiliza o tratamento, já que Freud se sente, de fato, enganado pela jovem.

Com o ensino de Lacan a respeito da "jovem homossexual" aprendemos que a vergonha demarcaria uma brecha a fim de que o Outro, como analista, possa, de alguma forma, intervir. Em relação à condução clínica de Freud: "[...] algo, ao que parece, lhe escapa, a saber, que se trata aí de uma verdadeira transferência, e que está aberto para ele o caminho da interpretação do desejo de enganar" (LACAN, 1995, p. 108). Mesmo ao conduzir a sua vida tendo como mola mestra a impossibilidade de satisfação, foi possível à "jovem homossexual” conceder uma abertura à intervenção de seu analista.

\section{Conclusão}

É muito mais interessante se pensar nas entrevistas preliminares como um campo possível à construção transferencial, mesmo que a demanda de tratamento se apresente de modo enviesado, referida à terceiros que não o próprio candidato à análise. $\mathrm{O}$ caso da jovem homossexual nos apresenta essa articulação, e Freud, para além da demanda inicial de tratamento dos pais de sua candidata à análise, possibilitou um cenário à condição transferencial, ao convidar a jovem a falar. Afinal, "O analista diz àquele que está para começar: 'Vamos lá, diga qualquer coisa, vai ser maravilhoso"” (LACAN, 1992, p. 50).

Sobre a posição do analista, não se trata, portanto, de supervalorizar os diagnósticos clínicos e seus sintomas, e nem mesmo de se ater demasiadamente a presença ou não de uma demanda de tratamento. Trata-se mais de compreender qual é o lugar, insistente, que o sujeito o oferta, ou seja, compreender como a condição transferencial se apresenta no decorrer do processo analítico. Caso contrário, o psicanalista pode muito bem se "enganar", como nos adverte Lacan (1995) referindo-se à posição de Freud no caso da jovem homossexual. A vergonha sinaliza que houve transferência, já que ela se apresenta na relação com o Outro, o que podemos observar desde as entrevistas preliminares. 


\section{Informação sobre a autora:}

\section{iD https://orcid.org/0000-0003-3512-3812}

http://lattes.cnpq.br/0843694215433301

Doutora em Psicologia/Estudos Psicanalíticos pela Universidade Federal de Minas Gerais (2016); Mestre em Psicologia/Estudos Psicanalíticos pela Universidade Federal de Minas Gerais (2007); Pós-Graduada em Psicologia Clínica pela Pontifícia Universidade Católica de Minas Gerais (2004), Graduada em Psicologia pela Fundação Mineira de Educação e Cultura (2001), sendo atualmente Psicóloga Clínica e Psicanalista autônoma e particular, como também conveniada com a Associação Mineira do Ministério Público, CEMIG-Saúde e DESBAN. É integrante da pesquisa "Transmissão e Filiação em populações em situação de vulnerabilidade", ofertado pelo Núcleo PSILACS (Psicanálise e Laço Social no Contemporâneo) da Universidade Federal de Minas Gerais. Exerce o cargo de professora e supervisora de estágio clínico em Psicanálise no curso de graduação em Psicologia da Faculdade Ciências da Vida em Sete Lagoas e professora do curso de graduação do Promove em Belo Horizonte. Ênfase da produção acadêmica e profissional junto aos temas de Psicanálise e Saúde Mental; Teoria e Clínica psicanalítica; Psicanálise e Laço social; Afetos e Contemporaneidade.

\section{Como citar este artigo:}

\section{ABNT}

NOGUEIRA, Anamaria Batista. Entrevistas preliminares: o caso da "jovem homossexual" de Sigmund Freud. Fractal: Revista de Psicologia, Niterói, v. 32, n. 2, p. 177-181, maio./ago. 2020. https://doi.org/10.22409/1984-0292/v32i2/5839

\section{APA}

Nogueira, A. B. (2020, Maio/Agosto). Entrevistas preliminares: o caso da "jovem homossexual" de Sigmund Freud. Fractal: Revista de Psicologia, 32(2), 177-181. doi: https://doi.org/10.22409/19840292/v32i2/5839

\section{Copyright:}

Copyright (C) 2020 Nogueira, A. B. Este é um artigo em acesso aberto distribuído nos termos da Licença Creative Commons Atribuição que permite o uso irrestrito, a distribuição e reprodução em qualquer meio desde que o artigo original seja devidamente citado.

Copyright (C) 2020 Nogueira, A. B. This is an Open Access article distributed under the terms of the Creative Commons Attribution License, which permits unrestricted use, distribution, and reproduction in any medium, provided the original article is properly cited.

\section{Referências}

FREUD, Sigmund. Lettre de Freud à Mrs N. N...: Correspondance de Freud 1873-1939 (1935). Paris: Gallimard, 1967.

FREUD, Sigmund. Um caso de histeria: tres ensaios sobre sexualidade e outros trabalhos (1901-1905). In: SALOMÃO, Jayme (Org.). Obras Psicológicas Completas de Sigmund Freud. Rio de Janeiro: Imago, 1996. v. 7, p. 119-229. Edição Standard Brasileira.

FREUD, Sigmund. O caso de Schereber: artigos sobre técnicas e outros trabalhos (1911-1913). In: SALOMÃO, Jayme (Org.). Obras Psicológicas Completas de Sigmund Freud. Rio de Janeiro: Imago, 1996. v. 12, p. 137-160. Edição Standard Brasileira.

FREUD, Sigmund. Além do princípio de prazer: psicologia de grupo e outros trabalhos (1920-1922). In: SALOMÃO, Jayme (Org.). Obras Psicológicas Completas de Sigmund Freud. Rio de Janeiro: Imago, 1996. v. 18, p. 157-186. Edição Standard Brasileira.

LACAN, Jacques. O seminário: o avesso da psicanálise. Rio de Janeiro: J. Zahar, 1992. livro 17.

LACAN, Jacques. O seminário: a relação de objeto. Rio de Janeiro: J. Zahar, 1995. livro 4.

LACAN, Jacques. Escritos (1958). Rio de Janeiro: J. Zahar, 1998.

MILLER, Jacques-Alain. As contra-indicações ao tratamento psicanalítico. Opção Lacaniana - Revista Brasileira Internacional de Psicanálise, n. 25, p. 52-55, 1999.

NOGUEIRA, Anamaria Batista. Incidências da vergonha na contemporaneidade. 2016. 246 f. Tese (Doutorado em Psicologia) - Universidade Federal de Minas Gerais, Belo Horizonte, 2016. Disponível em: https://repositorio.ufmg.br/ bitstream/1843/BUBD-ADCPXT/1/tese incid ncias da vergonha na contemporaneidade anamari.pdf. Acesso em: 29 fev. 2020. 